\title{
Uptake, translocation, and debromination of polybrominated diphenyl ethers in maize
}

\author{
Moming Zhao, Shuzhen Zhang*, Sen Wang, Honglin Huang \\ State Key Laboratory of Environmental Chemistry and Ecotoxicology, Research Center for Eco-Environmental Sciences, \\ Chinese Academy of Sciences, Beijing 100085, China. E-mail: zhaomoming@gmail.com
}

Received 23 March 2011; revised 23 May 2011; accepted 02 June 2011

\begin{abstract}
Uptake, translocation and debromination of three polybrominated diphenyl ethers (PBDEs), BDE-28, -47 and -99, in maize were studied in a hydroponic experiment. Roots took up most of the PBDEs in the culture solutions and more highly brominated PBDEs had a stronger uptake capability. PBDEs were detected in the stems and leaves of maize after exposure but rarely detected in the blank control plants. Furthermore, PBDE concentrations decreased from roots to stems and then to leaves, and a very clear decreasing gradient was found in segments upwards along the stem. These altogether provide substantiating evidence for the acropetal translocation of PBDEs in maize. More highly brominated PBDEs were translocated with more difficulty. Radial translocation of PBDEs from nodes to sheath inside maize was also observed. Both acropetal and radial translocations were enhanced at higher transpiration rates, suggesting that PBDE transport was probably driven by the transpiration stream. Debromination of PBDEs occurred in all parts of the maize, and debromination patterns of different parent PBDEs and in different parts of a plant were similar but with some differences. This study for the first time provides direct evidence for the acropetal translocation of PBDEs within plants, elucidates the process of PBDE transport and clarifies the debromination products of PBDEs in maize.
\end{abstract}

Key words: polybrominated diphenyl ethers; uptake; translocation; transport; debromination; maize

DOI: $10.1016 /$ S1001-0742(11)60748-1

\section{Introduction}

Polybrominated diphenyl ethers (PBDEs) are used around the world as flame retardants. They have been detected in various environmental matrices such as soil, water, air, sediments and biotic samples all over the world (de Wit et al., 2010; Frederiksen et al., 2009; Law et al., 2008; Zhu et al., 2009). PBDEs are persistent and bioaccumulative, and capable of acting as endocrine disruptors, carcinogens and neurodevelopmental toxicants (Darnerud et al., 2001; Frederiksen et al., 2009). Therefore, they present potential risks to human and animal health (de Wit et al., 2010).

Plant uptake is an important process when considering the risks associated with land contamination, the role of vegetation in the global cycling of persistent organic pollutants (Collins et al., 2006), and the potential of industrial discharges to contaminate the food chain (Darnerud et al., 2001). PBDEs have been reported to accumulate in plants (Huang et al., 2011) and are possibly further biomagnified through the food web (Frederiksen et al., 2009; Law et al., 2008). Therefore, studying their uptake and subsequent translocation in plants is important for food risk assessment.

For highly hydrophobic organic compounds (HOCs)

\footnotetext{
* Corresponding author. E-mail: szzhang@rcees.ac.cn
}

such as PBDEs, translocation from the roots was previously claimed to be insignificant compared with gaseous uptake, because these compounds tend to partition strongly into root epidermis and are difficult to transport acropetally to shoots (Collins et al., 2006; Liu and Schnoor, 2008; Zuo et al., 2006). However, recent studies have observed that HOCs can be taken up by plant roots and subsequently acropetally translocated (White et al., 2003; Zhang et al., 2009; Inui et al., 2008; Tao et al., 2009; Åslund et al., 2008), and their uptake and translocation vary with plant species and are influenced by chemical properties and other factors. Studies about plant uptake of PBDEs are very limited (Huang et al., 2010, 2011; Mueller et al., 2006; Vrkoslavová et al., 2010). In all the previously published studies, accumulation of PBDEs in both plant roots and shoots has been observed. Correlation analysis between PBDE concentrations in the soils and plant roots and shoots further suggested the possibility of their root uptake and subsequent acropetal translocation within plants (Huang et al., 2010). Nevertheless, direct evidence is still lacking to support such an interpretation, and efforts are needed to more accurately elucidate the PBDE transport inside plants with well-designed experiments and to explicitly understand the process of uptake and translocation.

Therefore, a hydroponic experiment was conducted in 
the present study to investigate the uptake and translocation of PBDEs in maize. BDE-28 (2,4,4'-triBDE), BDE-47 (2,2',4,4'-tetraBDE) and BDE-99 (2,2',4,4',5-pentaBDE) with $\log K_{\mathrm{ow}}$ values of 5.94, 6.81, and 7.32 were selected as representatives of tri-, tetra- and penta-BDEs, respectively. Distributions of these PBDEs and their debrominated products in different parts of maize as well as the accumulation gradient along heights and layers of stems and leaves were carefully studied with the goal of understanding their transport process.

\section{Materials and methods}

\subsection{Chemicals and reagents}

Standards of BDE-28, -47 and -99 and a standard solution containing 39 PBDEs were obtained from AccuStandard (USA). Standards of ${ }^{13}$ C-PCB-141 and ${ }^{13}$ C-PCB-208 were purchased from Cambridge Isotope Laboratory (USA). All solvents used, i.e., $n$-hexane, dichloromethane, acetone, methanol and chloroform, were of HPLC grade (J. T. Baker Solusorb, USA). Anhydrous sodium sulfate $\left(\mathrm{Na}_{2} \mathrm{SO}_{4}\right)$, silica gel and alumina (100-200 mesh) used for sample cleanup were washed with hexane and heated overnight at $150^{\circ} \mathrm{C}$.

A standard of each PBDE congener was respectively dissolved in acetone and added to pre-aerated full-strength Hoagland nutrient solution prepared with deionized water. Concentrations in the exposure solutions were determined to be $20.54,15.50$ and $4.76 \mathrm{ng} / \mathrm{mL}$ for BDE-28, -47 and -99 , respectively. Each solution was prepared immediately prior to exposure and mixed thoroughly to ensure complete dissolution.

\subsection{Hydroponic exposure}

Maize seeds (Zea mays L. cv. Zhengdan 1, obtained from the Chinese Academy of Agricultural Sciences, China) were first sterilized in $3 \%(\mathrm{~m} / \mathrm{m}) \mathrm{H}_{2} \mathrm{O}_{2}$ solution for 30 min, followed by thoroughly washing with deionized water, and subsequently germinated on moist filter paper at $27^{\circ} \mathrm{C}$ in the dark for 5 days. Then seedlings were selected, transferred to containers filled with $1.8 \mathrm{~L}$ of $1 / 3$ strength Hoagland nutrient solution and cultivated in a growth chamber at $25^{\circ} \mathrm{C}$ for $14 \mathrm{hr}$ (day cycle) and $20^{\circ} \mathrm{C}$ for $10 \mathrm{hr}$ (night cycle) each day. The nutrient solution was renewed every day and kept aerated.

Sixteen days later, for each treatment, four selected plants were transferred to a glass bottle used as a reactor, filled with $200 \mathrm{~mL}$ of the desired exposure solution. Three replicates of each treatment were set up. A plantfree control and a PBDE-free blank were included in each treatment. Each reactor was fitted with a drilled stopper and wrapped with aluminum foil to avoid possible photodegradation of PBDEs, and the stems were wrapped with urethane sponge to avoid injury and keep the reactor sealed. The solutions were no longer aerated to prevent loss of PBDEs through volatilization. The initial height of the solution surface was marked, and pre-aerated Hoagland nutrient solution was added every day to the marked line to replace any losses. The decrease in the amount of solution in one day was considered to be the transpiration rate (Murano et al., 2010). Exposure experiments of the three PBDEs were conducted separately to avoid the complexity resulting from PBDE debromination and volatilization.

\subsection{Sampling and analysis}

Maize plants were sampled at intervals of 1,3 and 6 days. Roots and stem parts inside the reactor were first carefully rinsed with deionized water to remove any adhering PBDEs, and the rinse water was collected and combined into the exposure solution. The whole plants were then rinsed thoroughly with deionized water, blotted and separated into roots, stems and leaves, and the stems were further divided into four parts from roots upwards as displayed in Fig. 1. All the samples were then frozen at $-50^{\circ} \mathrm{C}$ overnight, freeze-dried for $48 \mathrm{hr}$ in a lyophilizer (FD-1, Beijing Boyikang Instrument Ltd., China), and weighed to determine their dry weights. The dried samples were chopped finely and stored in glass containers at $-20^{\circ} \mathrm{C}$ before chemical analysis.

Extraction of PBDEs in solutions and plant samples was performed following the methods described elsewhere (Huang et al., 2010; López et al., 2009) with minor modifications. Briefly, solution samples were solvent-extracted three times with dichloromethane in separating funnels, dehydrated with anhydrous sodium sulfate, concentrated and solvent-exchanged to $n$-hexane. Plant samples were Soxhlet extracted with $100 \mathrm{~mL}$ of hexane/acetone $(1: 1, V / V)$ at $65^{\circ} \mathrm{C}$ for $24 \mathrm{hr}$, fractionated on a multilayer silica-alumina column and eluted with $70 \mathrm{~mL}$ of hexane/dichloromethane $(1: 1, V / V)$, concentrated and solvent-exchanged to $n$-hexane. ${ }^{13} \mathrm{C}$-PCB-141 and ${ }^{13} \mathrm{C}$ PCB-208 were used as surrogate standard and internal standard, respectively.

The BDE-28 treatment was taken as the example to further investigate the layered distribution of PBDEs in stems and leaves. BDE-28 in stem and leaf cuticles was extracted following reported methods (Kaupp et al., 2000; Lin et al., 2007) with some modifications. Briefly, fresh stems and leaves were separately immersed in 20 and 50 $\mathrm{mL}$ of a chloroform and methanol mixture $(3: 1, V / V)$ for

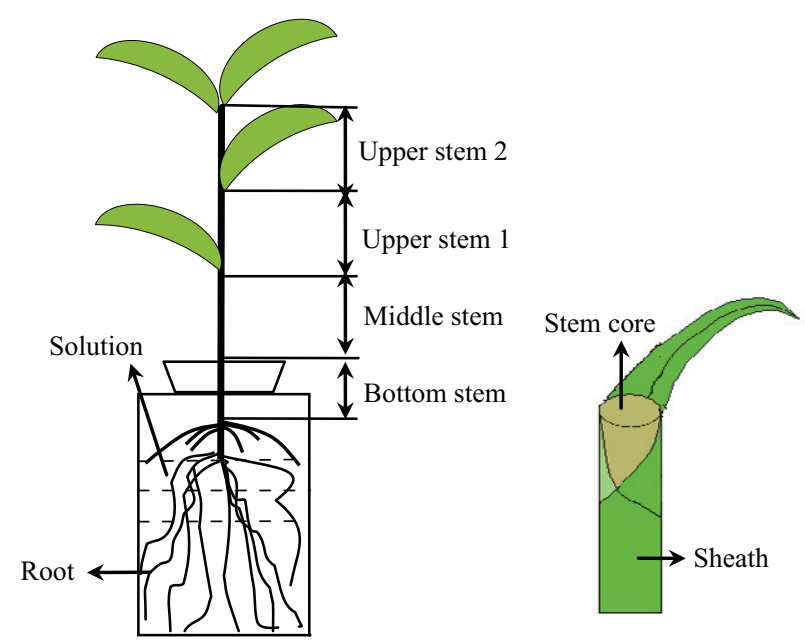

Fig. 1 Schematic of the hydroponic exposure reactor and sampling. 
$15 \mathrm{sec}$. The extracts were then sulfonated with concentrated sulfuric acid, purified with a multilayer silica-alumina column, concentrated and dissolved in $n$-hexane and analyzed; the result represents the PBDEs in cuticles. ${ }^{13} \mathrm{C}$ PCB-141 and ${ }^{13} \mathrm{C}$-PCB-208 were also used as surrogate standard and internal standard, respectively. The immersed stems were further separated into stem core and sheath fractions (Ritchie et al., 1992). The materials of stem cores, sheathes and leaves after the removal of cuticular PBDEs were freeze-dried and subjected to Soxhlet extraction and cleanup by the same method mentioned above for plant tissues.

Sample analysis was performed with an Agilent 7890 GC-MS (5975 inert) (Agilent, USA). A HP-5MS column $(30 \mathrm{~m} \times 0.25 \mathrm{~mm} \times 0.25 \mu \mathrm{m})(\mathrm{J} \& \mathrm{~W}$ Scientific, USA $)$ was used for determination of the PBDEs. The carrier gas was helium at a flow rate of $1.5 \mathrm{~mL} / \mathrm{min}$. The temperature program was as follows: oven temperature held at $110^{\circ} \mathrm{C}$ for $1 \mathrm{~min}$, increased at $30^{\circ} \mathrm{C} / \mathrm{min}$ to $200^{\circ} \mathrm{C}$ and held for $1 \mathrm{~min}$, followed by a temperature increase of $3^{\circ} \mathrm{C} / \mathrm{min}$ to $260^{\circ} \mathrm{C}$ and held for $12.5 \mathrm{~min}$, and then increased at $20^{\circ} \mathrm{C} / \mathrm{min}$ to $295^{\circ} \mathrm{C}$ and held for $27.75 \mathrm{~min}$. A $1-\mu \mathrm{L}$ aliquot of the extracted sample was injected into the GC column in pulsed splitless injection mode. The compounds were monitored at $m / z$ 250, 328, 407.8, 485.7 and 563.7 for mono- through penta-BDEs, respectively. PBDE concentrations in plant samples in this study are all expressed on a dry weight (dw) basis.

\subsection{QA/QC}

Quality assurance and quality control were done by regular analyses of procedural blanks, blind duplicate samples, and random injection of solvent blanks and standards. The method detection limits (MDLs), defined as a signal of 3 times the noise level, ranged from 3 to $46 \mathrm{pg} / \mathrm{g}$ for all the PBDE congeners. Recovery of ${ }^{13} \mathrm{C}-\mathrm{PCB}-141$ was $(95.8 \pm 11.0) \%$. Recoveries of PBDE congeners ranged from $91.0 \%$ to $114.5 \%$ with relative standard deviations $<8 \%$ in three spiked solution samples (PBDE congeners spiked into Hoagland solution), from $81.9 \%$ to $120.1 \%$ with relative standard deviations $<10 \%$ in three spiked blank samples (PBDE congeners spiked into anhydrous sodium sulfate) and from $68.9 \%$ to $125.5 \%$ with relative standard deviations $<15 \%$ in matrix spiked samples (PBDE congeners spiked into non-PBDE contaminated plant samples collected after cultivation and before exposure, including maize root, leaf and segmented stem components, each component containing three duplicates).

\section{Results and discussion}

\subsection{Plant growth}

Maize exhibited no obvious toxicity symptoms when exposed to PBDEs compared with the control plants without contamination exposure. Plants did not grow significantly during the exposure period with the exception of leaves, whose biomasses first decreased slightly and then increased to approximately $120 \%$ of their original weights.
Similarly, the transpiration rate (Fig. 2) first decreased and then increased when new leaves started growing after 3-4 days.

\subsection{Uptake of PBDEs by maize roots}

Concentrations of PBDEs in plant tissues (roots, stems and leaves) after different exposure times are shown in Fig. 3. The PBDE concentrations in maize roots reached the highest levels after one day and then decreased, and the decrease was more significant for the lower-brominated PBDEs. The total amounts of PBDEs in maize plants per cultivation bottle were in the range of 1.22-24.16 ng in stems and $0.20-7.17 \mathrm{ng}$ in leaves for different congeners and different exposure times, which were trivial compared with the decreases in their accumulation in roots (148.3-818 ng). Therefore, the contribution of root-toshoot translocation of PBDEs to their decreases in roots was negligible. The decrease of PBDEs in roots could be partially caused by their microbial and enzymatic degradation (Huang et al., 2011; Ucisik and Trapp, 2008) which was enhanced by the interactions between plant roots and microbes (Leigh et al., 2006). Furthermore, reduced PBDE concentrations in the exposure solutions could also contribute to the reduction of PBDE concentrations in roots. Analysis showed that concentrations of the PBDEs in the solutions decreased to $2.10,0.95$ and $0.39 \mathrm{ng} / \mathrm{mL}$ for BDE-28, -47 and -99 , respectively, after one day of plant exposure. Subsequently the BDE-28 concentration in the solution continued to decrease and reached 0.57 $\mathrm{ng} / \mathrm{mL}$, while BDE-47 had a slight decrease and BDE99 showed almost no change. Root concentration factors (RCFs), calculated as the ratio of the concentration in roots to that in the exposure solution (Trapp, 2000), were 4003.8, 6410.2 and 7304.1 for BDE-28, -47 and -99 respectively after one day of exposure, confirming the higher root uptake of compounds with higher $K_{\text {ow }}$ values (Burken and Schnoor, 1998; Lin et al., 2007; Liu and Schnoor, 2008).

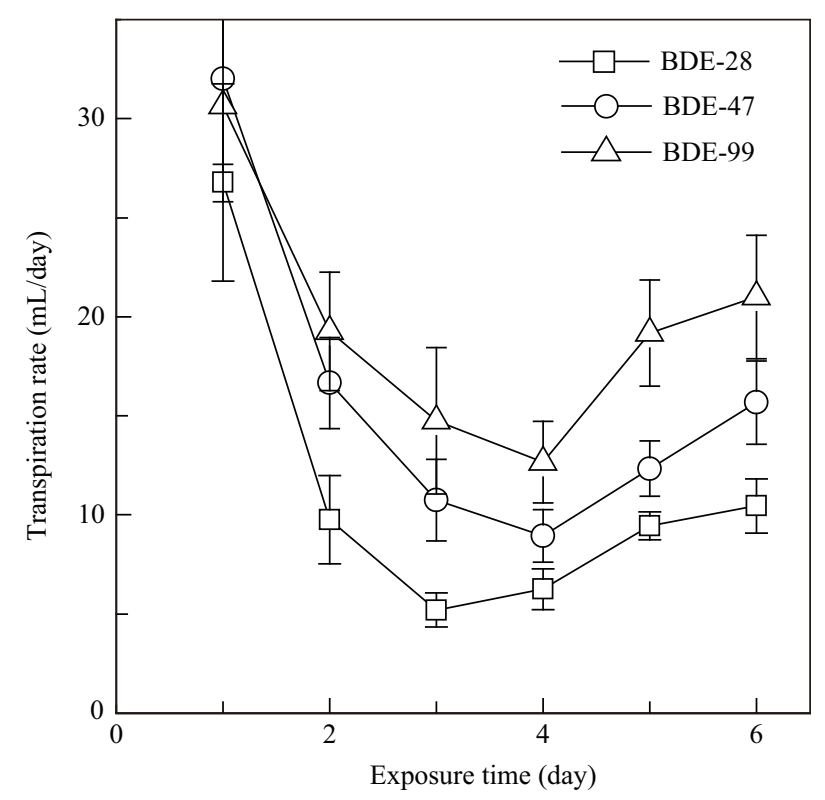

Fig. 2 Transpiration rate of maize at different exposure times. 


\subsection{Acropetal distribution of PBDEs in maize}

All three PBDEs were detected in maize stems and leaves although their amounts were small. A gradient distribution from the roots upwards was observed as shown in Fig. 3, which could be a sign of their acropetal translocation inside plants (Huang et al., 2010, 2011; Liu and Schnoor, 2008). The average ratios of PBDE concentrations in roots to stems to leaves calculated using the average concentrations at different exposure times were 849:4.8:1, 1909:6.9:1, and 9031:22:1 for BDE-28, -47 and -99, respectively, indicative of their limited acropetal transport from roots to leaves, particularly for the more highly lipophilic PBDEs. Concentrations of all the PBDEs in stems reached the highest levels on the first day and then decreased; however, the concentrations ceased to decrease or even increased again after 3 days of exposure. Concentrations of BDE28 and -47 in leaves were the highest on the first day and then decreased, while concentrations of BDE-99 continued to increase slightly after the first day. The accumulation of PBDEs in stems and leaves was a dynamic process, which might be determined by a combination of acropetal translocation, gaseous uptake (Collins et al., 2006), enzymic degradation (Liu et al., 2009), phytovolatilization (Baduru et al., 2008), and photodegradation (Collins et al., 2006), etc.

To further substantiate the existence of acropetal translocation and better understand the transport pathway, the distribution of PBDEs in segmented stems was investigated (Fig. 4). Concentrations of PBDEs were the highest in the bottom stems and then gradually decreased upwards, but no significant differences were noted between the concentrations in the upper stems $(p>0.05)$. This gradient distribution pattern provides additional substantiating evidence for the acropetal translocation of the PBDEs in stems. Concentrations of the PBDEs in the bottom stems first decreased and then increased after 3 days of exposure, which followed the same time trend as the changes in transpiration rate (Fig. 2). Furthermore, the PBDE concentration in the bottom stems was significantly
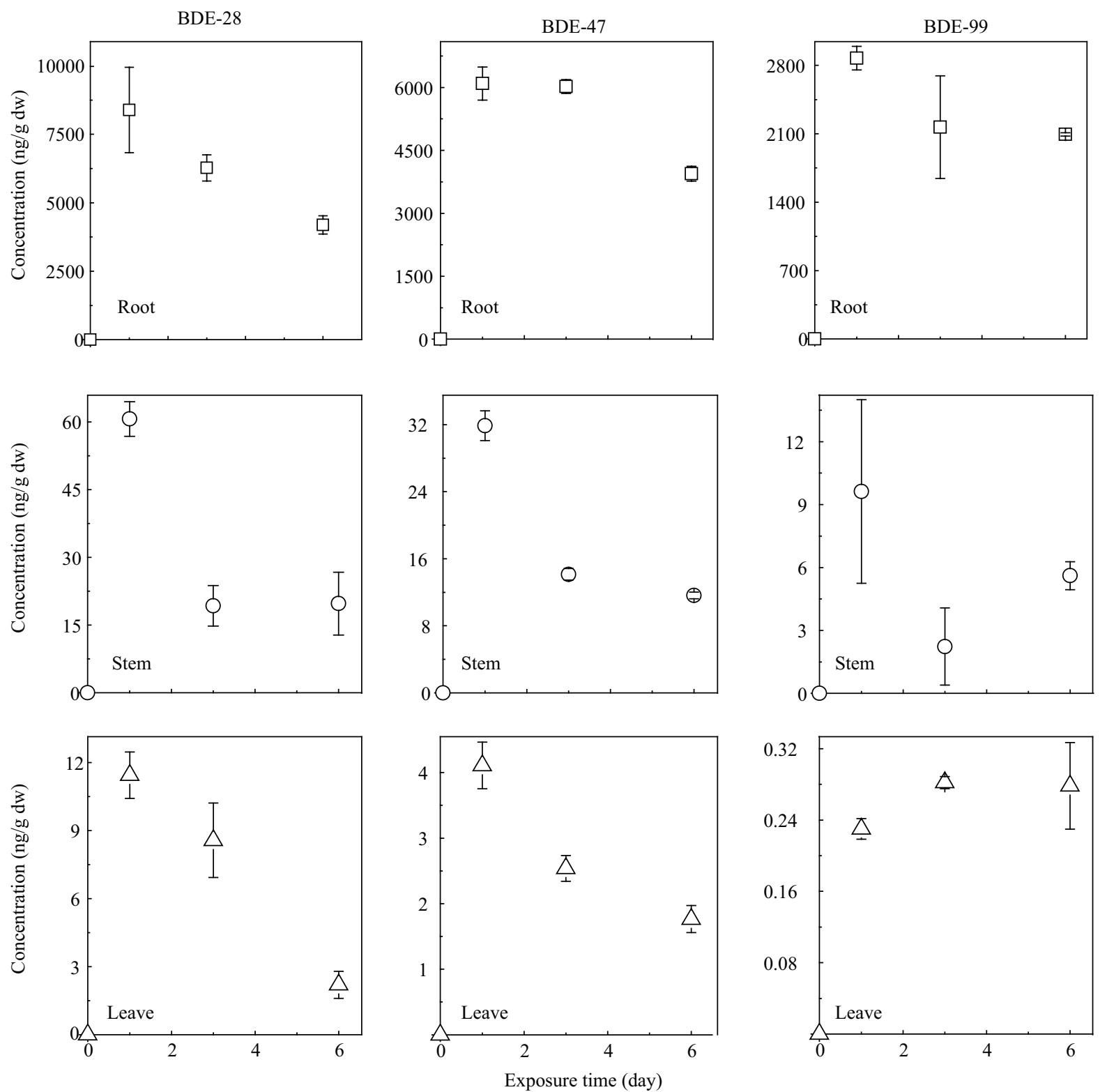

Fig. 3 Concentrations of PBDEs in plant tissues. 

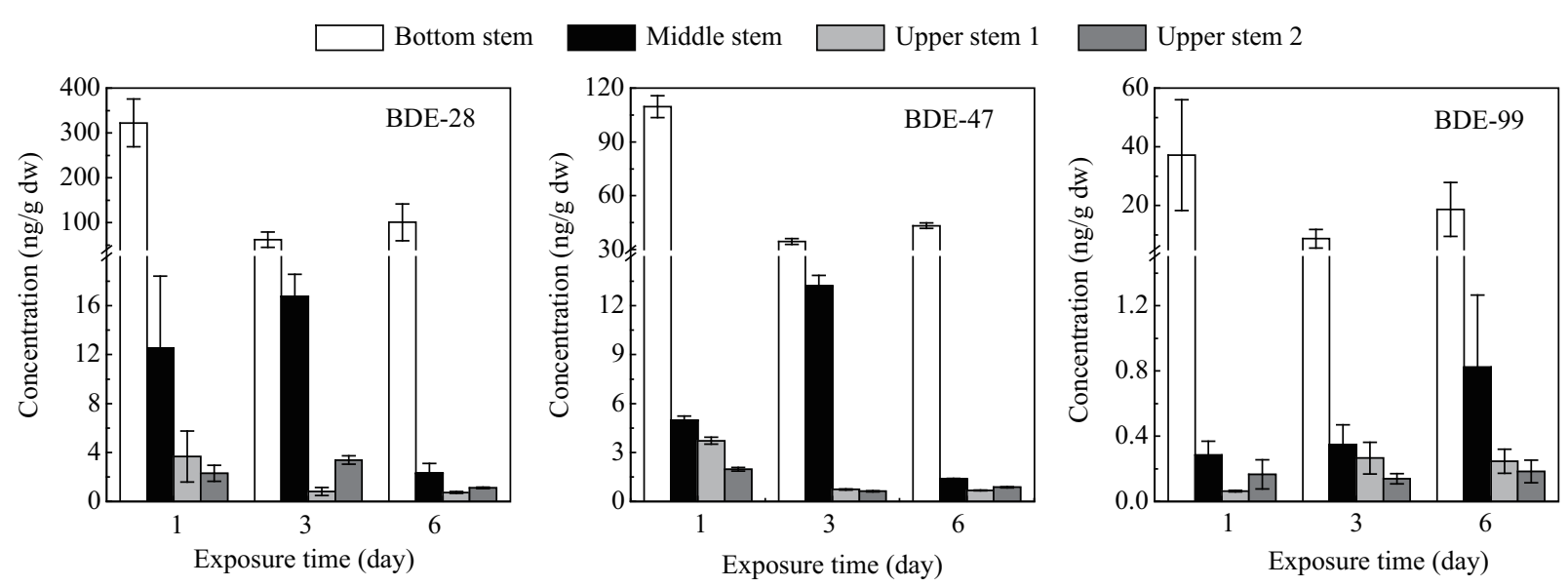

Fig. 4 Concentrations of PBDEs in stems.

correlated with the transpiration rate ( $p<0.001$, Fig. 5), indicating possible transport of PBDEs from roots to stems via transpiration (Burken and Schnoor, 1998; Collins et al., 2006; Murano et al., 2010). However, for the middle stems, concentrations of BDE-28 and -47 reached the highest levels on day 3 and then decreased, while concentrations of BDE-99 kept increasing (Fig. 4). There was an apparent retardation of PBDE transport from the bottom stems upwards. A similar observation for lindane translocation in wheat has been reported (Li et al., 2005). Redistribution of PBDEs and PCBs within plants was reported to kinetically limit their accumulation (Huang et al., 2011; Pier et al., 2002), which might explain the retardation of PBDE distribution in the middle stems compared with that in the bottom section. Concentrations of BDE-28 and -47 in the upper stems decreased after 1 day of exposure, while the concentration of BDE-99 consistently increased. This trend was the same as that of PBDE concentrations in leaves and suggested the higher capability of BDE-99 to be retained in plant tissues despite its difficulty in acropetal translocation.

It is possible that PBDEs in the culture solution evaporate into the ambient air and enter plants via gaseous uptake, contributing to their accumulation in maize. In order to identify the contribution of acropetal transport of PBDEs in plants to their accumulation in stems and leaves, PBDE concentrations in the blank control plants were determined (Table 1) and considered to be due to their gaseous uptake, on the assumption that PBDEs evenly diffuse in the ambient air and equally absorb onto shoot tissues of exposed plants and their nearby blank control plants (Tao et al., 2009; Zhang et al., 2009). PBDEs were only detected in the leaf and some upper stem samples, confirming that evaporation of PBDEs was wellprevented by fitting the reactor with a drilled stopper and wrapping plant stems with urethane sponge to keep the reactor sealed. The concentrations decreased with increasing exposure time as well as with increasing $K_{\text {ow }}$ value. The ratios of PBDEs from gaseous uptake to the total accumulation in stems and leaves $\left(C_{\text {blank }} / C_{\text {exposed }}\right.$, listed in Table 1) were mostly below $18 \%$ and decreased with increasing exposure time, indicating that the contribution of gaseous uptake to their accumulation in stems and leaves was limited and, more importantly, acropetal translocation would gradually dominate PBDE accumulation in plants although it was slower than gaseous uptake. Furthermore, more highly lipophilic PBDEs had higher ratios, further suggesting their lower acropetal translocation, which is in accordance with the results obtained by Tao et al. (2009).

\subsection{Layered distribution of PBDEs in stems and leaves}

Layered distribution of PBDEs in stems and leaves was investigated by taking BDE-28 as an example to differentiate between interior translocation from roots and exterior gaseous uptake. The amounts of BDE-28 in cuticles only accounted for a small portion of the total BDE-28 in stems and leaves (Table 2). This fraction represents BDE-28 embedded in the wax cuticle and should be the major sink
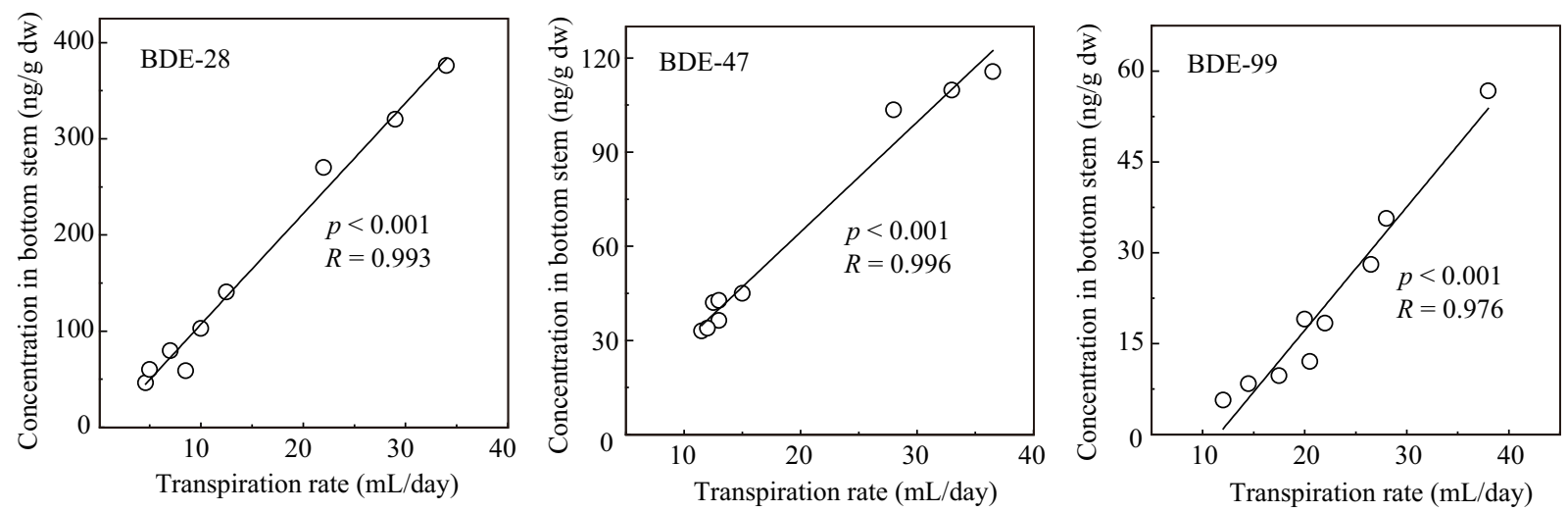

Fig. 5 Relationship between PBDE concentration in bottom stems and transpiration rate. 
Table 1 Concentrations of PBDEs in maize shoots of blank control plants and ratios of PBDEs from gaseous uptake to their total accumulation in shoots

\begin{tabular}{|c|c|c|c|c|c|c|c|c|c|}
\hline \multirow[t]{2}{*}{ Compound } & \multirow{2}{*}{$\begin{array}{l}\text { Exposure } \\
\text { time (day) }\end{array}$} & \multicolumn{2}{|c|}{ Bottom stem } & \multicolumn{2}{|c|}{ Middle stem } & \multicolumn{2}{|c|}{ Upper stem } & \multicolumn{2}{|c|}{ Leaf } \\
\hline & & $\begin{array}{l}C_{\text {blank }^{a}}{ }^{\mathrm{ng} / \mathrm{g})} \\
\end{array}$ & Ratio $^{\mathrm{b}}(\%)$ & $\begin{array}{l}C_{\text {blank }} \\
(\mathrm{ng} / \mathrm{g})\end{array}$ & $\begin{array}{l}\text { Ratio } \\
(\%)\end{array}$ & $\begin{array}{l}C_{\text {blank }} \\
(\mathrm{ng} / \mathrm{g})\end{array}$ & $\begin{array}{l}\text { Ratio } \\
(\%)\end{array}$ & $\begin{array}{l}C_{\text {blank }} \\
(\mathrm{ng} / \mathrm{g})\end{array}$ & $\begin{array}{l}\text { Ratio } \\
(\%)\end{array}$ \\
\hline \multirow[t]{3}{*}{ BDE-28 } & 1 & n.d. & - & 0.0902 & 0.72 & 0.4616 & 15.2 & 1.1582 & 10.1 \\
\hline & 3 & n.d. & - & n.d. & - & n.d. & - & 0.7246 & 8.46 \\
\hline & 6 & n.d. & - & n.d. & - & n.d. & - & 0.1732 & 7.88 \\
\hline \multirow[t]{3}{*}{ BDE-47 } & 1 & n.d. & - & n.d. & - & 0.3730 & 12.8 & 0.6189 & 15.1 \\
\hline & 3 & n.d. & - & n.d. & - & n.d. & - & 0.2592 & 10.2 \\
\hline & 6 & n.d. & - & n.d. & - & n.d. & - & 0.1382 & 7.83 \\
\hline \multirow[t]{3}{*}{ BDE-99 } & 1 & n.d. & - & 0.0124 & 4.36 & 0.0179 & 17.8 & 0.0946 & 41.1 \\
\hline & 3 & n.d. & - & 0.0064 & 1.85 & n.d. & - & 0.0522 & 18.5 \\
\hline & 6 & n.d. & - & 0.0050 & 0.61 & n.d. & - & 0.0255 & 9.17 \\
\hline
\end{tabular}

${ }^{\mathrm{a}}$ Mean value, $n=2 ;{ }^{\mathrm{b}}$ defined as the ratio of PBDE concentrations in the blank control plants and in the exposed plants, ratio $=C_{\mathrm{blank}} / C_{\text {exposed }}$. n.d.: not detected; -: not applicable.

Table 2 Layered distribution of BDE-28 in shoots (unit: $\mathrm{ng} / \mathrm{g} \mathrm{dw}$ basis) ${ }^{\mathrm{a}}$

\begin{tabular}{llllr}
\hline Exposure time & Leaf & Leaf cuticle & Stem core & Sheath \\
\hline 1 day & $14.82 \pm 0.97$ & $0.38 \pm 0.03$ & $22.68 \pm 8.64$ & $28.80 \pm 4.34$ \\
3 days & $6.78 \pm 0.61$ & $0.45 \pm 0.23$ & $51.95 \pm 17.87$ & $10.55 \pm 2.73$ \\
6 days & $2.16 \pm 0.16$ & $0.60 \pm 0.39$ & $16.02 \pm 2.03$ & $9.82 \pm 2.41$ \\
\hline
\end{tabular}

${ }^{\text {a }}$ Mean value \pm standard deviation, $n=3$.

for PBDEs through gaseous uptake (Kaupp et al., 2000; Lin et al., 2007). Therefore, we can draw a reasonable conclusion that gaseous uptake from the ambient air played a negligible role in BDE-28 accumulation in stems and leaves in this controlled experiment. This further rules out the possibility that BDE-28 volatilization from the solution induced its gradient distribution in stems, thus further substantiating its significant acropetal translocation in maize.

Apart from the acropetal transport demonstrated above, radial transport of PBDEs from the nodes to sheath via transverse bundles is also possible along with the transpiration stream (Shane et al., 2000). In this study, BDE-28 was detected in the sheath and its concentration was lower than or nearly equal to that in the corresponding stem cores (Table 2), confirming the radial translocation of BDE-28 to sheath. The ratio of BDE-28 concentration in the sheath to that in the stem core $\left(C_{\text {sheath }} / C_{\text {stem core }}\right)$ was further calculated and plotted against the transpiration rate at different sample times (Fig. 6), showing an obvious increase of the ratio with the increase of the transpiration rate. This suggests that the partition of BDE-28 between sheath and stem core was probably affected by transpiration, agreeing with the above speculation that the radial transport of BDE-28 also occurred via transpiration.

\subsection{Debromination products}

Figure 7 shows the percentage profiles of the debromination products of BDE-28, -47 and -99 in each part of maize. BDE-28 could be debrominated to BDE-15, -12/13 (co-eluting congeners) and -8; BDE-47 could be debrominated to BDE-28, $-15,-12 / 13$ and -8 ; BDE-99 could be debrominated to BDE-66, -49, -47, -28, -15, -12/13 and -11 . BDE-15 was prevalent in the debromination products of all three parent PBDEs probably due to its low enthalpy of formation (Zeng et al., 2008). As for BDE-99, BDE-47

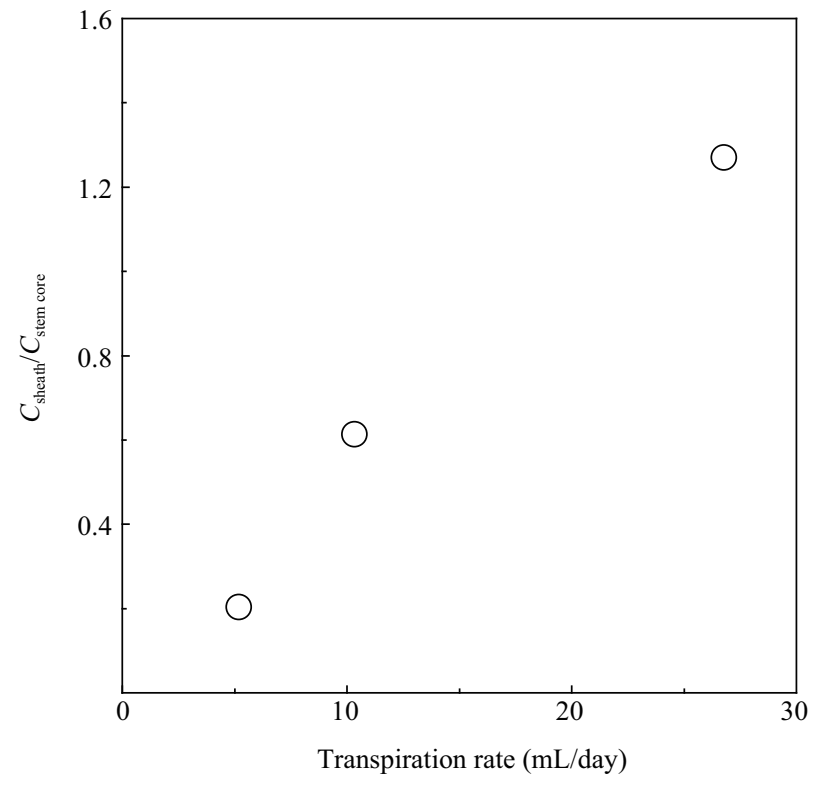

Fig. 6 Relationship between $C_{\text {sheath }} / C_{\text {stem core }}$ value and transpiration rate.

was another predominant product while the other two tetraBDE products (BDE-49 and -66) were only found in leaves at low levels, similar to the case of BDE-99 debromination by carp and microbes (Noyes et al., 2010; Robrock et al., 2008). BDE-12/13 (3,4-diBDE/2,4'-diBDE) was detected in plants exposed to any of the three parent PBDEs and BDE-11 (3,3'-diBDE) was detected in BDE-99 exposed plants, indicating the possibility of the rearrangement of bromine, especially for BDE-99. Formation of BDE-11 and BDE-13 could also be ascribed to their low enthalpies of formation (Zeng et al., 2008). Most varieties of PBDEs were detected in leaves, followed by stems and then roots, which could be due to either the differences in metabolism of PBDEs among roots, stems and leaves or translocation of the debromination products from roots to stems and 


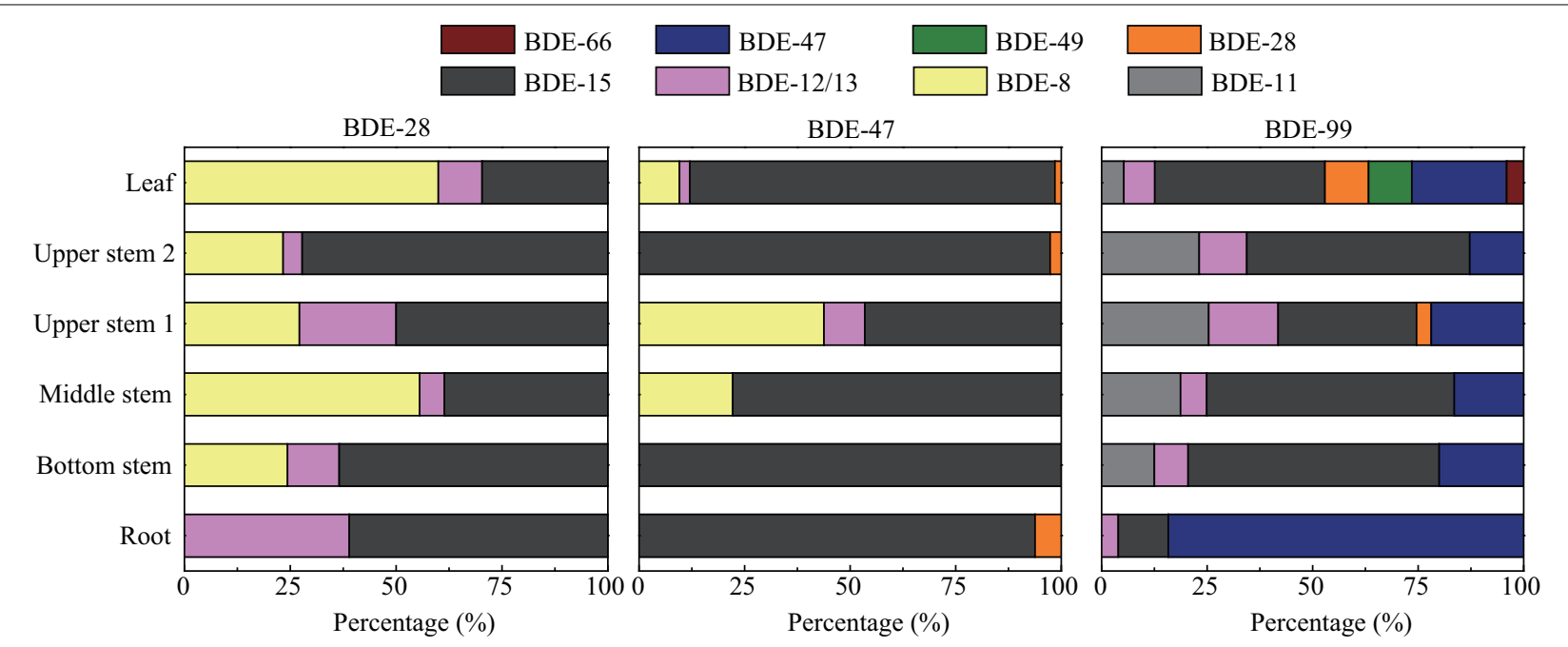

Fig. 7 Percentage distribution of debromination products of PBDEs in maize.

further to leaves.

\section{Conclusions}

This work observed the accumulation of BDE-28, -47 and -99 in all parts of maize plants and for the first time proved the limited but significant acropetal transport of PBDEs in maize and elucidated the transport process. Roots took up a large portion of PBDEs, and the more highly brominated PBDEs had stronger uptake capability. The gradient distribution of PBDEs from roots upwards, especially the gradient within stems, clearly demonstrated the acropetal transport of PBDEs in maize, and the more highly brominated PBDEs had weaker translocation capability. Radial transport of PBDEs from nodes to sheath was also likely to occur, suggested by the distribution of BDE28 in different layers of stems. Both acropetal and radial translocations in maize were related to the transpiration rate, suggesting that $\mathrm{PBDE}$ transport was probably driven by the transpiration stream. Debromination occurred in all parts of maize, while similarities and differences in debromination patterns were found among different parent PBDEs and in different tissues.

\section{Acknowledgments}

This work was supported by the National Basic Research Program (973) of China (No. 2009CB421603) and the National Natural Science Foundation of China (No. 40730740, 20921063, 20807048).

\section{References}

Åslund M L W, Rutter A, Reimer K J, Zeeb B A, 2008. The effects of repeated planting, planting density, and specific transfer pathways on PCB uptake by Cucurbita pepo grown in field conditions. Science of the Total Environment, 405(13): 14-25.

Baduru K K, Trapp S, Burken J G, 2008. Direct measurement of VOC diffusivities in tree tissues: Impacts on tree-based phytoremediation and plant contamination. Environmental Science $\mathcal{E}$ Technology, 42(4): 1268-1275.

Burken J G, Schnoor J L, 1998. Predictive relationships for uptake of organic contaminants by hybrid poplar trees. Environmental Science E Technology, 32(21): 3379-3385.

Collins C, Fryer M, Grosso A, 2006. Plant uptake of non-ionic organic chemicals. Environmental Science E Technology, 40(1): 45-52.

Darnerud P O, Eriksen G S, Jóhannesson T, Larsen P B, Viluksela M, 2001. Polybrominated diphenyl ethers: Occurrence, dietary exposure, and toxicology. Environmental Health Perspectives, 109(Suppl. 1): 49-68.

de Wit C A, Herzke D, Vorkamp K, 2010. Brominated flame retardants in the Arctic environment - trends and new candidates. Science of the Total Environment, 408(15): 2885-2918.

Frederiksen M, Vorkamp K, Thomsen M, Knudsen L E, 2009. Human internal and external exposure to PBDEs - A review of levels and sources. International Journal of Hygiene and Environmental Health, 212(2): 109-134.

Huang H L, Zhang S Z, Christie P, Wang S, Xie M, 2010. Behavior of decabromodiphenyl ether (BDE-209) in the soil-plant system: uptake, translocation, and metabolism in plants and dissipation in soil. Environmental Science $\mathcal{E}$ Technology, 44(2): 663-667.

Huang H L, Zhang S Z, Christie P, 2011. Plant uptake and dissipation of PBDEs in the soils of electronic waste recycling sites. Environmental Pollution, 159(1): 238-243.

Inui H, Wakai T, Gion K, Kim Y S, Eun H, 2008. Differential uptake for dioxin-like compounds by zucchini subspecies. Chemosphere, 73(10): 1602-1607.

Kaupp H, Blumenstock M, McLachlan M S, 2000. Retention and mobility of atmospheric particle-associated organic pollutant PCDD/Fs and PAHs in maize leaves. New Phytologist, 148(3): 473-480.

Law R J, Herzke D, Harrad S, Morris S, Bersuder P, Allchin $\mathrm{C}$ R, 2008. Levels and trends of HBCD and BDEs in the European and Asian environments, with some information for other BFRs. Chemosphere, 73(2): 223-241.

Leigh M B, Prouzova P, Mackova M, Macek T, Nagle D P, Fletcher J S, 2006. Polychlorinated biphenyl (PCB)-degrading bacteria associated with trees in a PCB-contaminated site. Applied and Environmental Microbiology, 72(4): 23312342.

Li H, Sheng G Y, Chiou C T, Xu O Y, 2005. Relation of organic contaminant equilibrium sorption and kinetic uptake in plants. Environmental Science E Technology, 39(13): 48644870. 
Lin H, Tao S, Zuo Q, Coveney R M, 2007. Uptake of polycyclic aromatic hydrocarbons by maize plants. Environmental Pollution, 148(2): 614-619.

Liu J Y, Schnoor J L, 2008. Uptake and translocation of lesserchlorinated polychlorinated biphenyls (PCBs) in whole hybrid poplar plants after hydroponic exposure. Chemosphere, 73(10): 1608-1616.

Liu J Y, Hu D F, Jiang G B, Schnoor J L, 2009. In vivo biotransformation of 3,3',4,4'-tetrachlorobiphenyl by whole plants-poplars and switchgrass. Environmental Science $\mathcal{E}$ Technology, 43(19): 7503-7509.

López P, Brandsma S A, Leonards P E G, De Boer J, 2009. Methods for the determination of phenolic brominated flame retardants, and by-products, formulation intermediates and decomposition products of brominated flame retardants in water. Journal of Chromatography A, 1216(3): 334-345.

Mueller K E, Mueller-Spitz S R, Henry H F, Vonderheide A P, Soman R S, Kinkle B K et al., 2006. Fate of pentabrominated diphenyl ethers in soil: Abiotic sorption, plant uptake, and the impact of interspecific plant interactions. Environmental Science $\mathcal{E}$ Technology, 40(21): 6662-6667.

Murano H, Otani T, Seike N, Sakai M, 2010. Dieldrin uptake and translocation in plants growing in hydroponic medium. Environmental Toxicology and Chemistry, 29(1): 142148.

Noyes P D, Kelly S M, Mitchelmore C L, Stapleton H M, 2010. Characterizing the in vitro hepatic biotransformation of the flame retardant BDE 99 by common carp. Aquatic Toxicology, 97(2): 142-150.

Pier M D, Zeeb B A, Reimer K J, 2002. Patterns of contamination among vascular plants exposed to local sources of polychlorinated biphenyls in the Canadian Arctic and Subarctic. Science of the Total Environment, 297(1-3): 215-227.

Ritchie S W, Hanway J J, Benson G, 1992. How a corn plant develops. In: Special Report No. 48 of Cooperative Extension Service. Iowa State University of Science and Technology. Ames, IA, USA.

Robrock K R, Korytar P, Alvarez-Cohen L, 2008. Pathways for the anaerobic microbial debromination of polybrominated diphenyl ethers. Environmental Science E Technology, 42(8): 2845-2852.
Shane M W, McCully M E, Canny M J, 2000. The vascular system of maize stems revisited: Implications for water transport and xylem safety. Annals of Botany, 86(2): 245258.

Tao Y Q, Zhang S Z, Zhu Y G, Christie P, 2009. Uptake and acropetal translocation of polycyclic aromatic hydrocarbons by wheat (Triticum aestivum L.) grown in field-contaminated soil. Environmental Science $\mathcal{E}$ Technology, 43(10): 3556-3560.

Trapp S, 2000. Modelling uptake into roots and subsequent translocation of neutral and ionisable organic compounds. Pest Management Science, 56(9): 767-778.

Ucisik A S, Trapp S, 2008. Uptake, removal, accumulation, and phytotoxicity of 4-chlorophenol in willow trees. Archives of Environmental Contamination and Toxicology, 54(4): 619627.

Vrkoslavová J, Demnerová K, Macková M, Zemanová T, Macek T, Hajslová J et al., 2010. Absorption and translocation of polybrominated diphenyl ethers (PBDEs) by plants from contaminated sewage sludge. Chemosphere, 81(3): 381386.

White J C, Wang X P, Gent M P N, Iannucci-Berger W, Eitzer B D, Schultes N P et al., 2003. Subspecies-level variation in the phytoextraction of weathered $p, p^{\prime}$-DDE by Cucurbita pepo. Environmental Science $\mathcal{E}$ Technology, 37(19): 43684373.

Zeng X, Simonich S L M, Robrock K R, Korytár P, AlvarezCohen L, Barofsky D F, 2008. Development and validation of a congener-specific photodegradation model for polybrominated diphenyl ethers. Environmental Toxicology and Chemistry, 27(12): 2427-2435.

Zhang H J, Chen J P, Ni Y W, Zhang Q, Zhao L, 2009. Uptake by roots and translocation to shoots of polychlorinated dibenzo- $p$-dioxins and dibenzofurans in typical crop plants. Chemosphere, 76(6): 740-746.

Zhu L Y, Ma B L, Hites R A, 2009. Brominated flame retardants in serum from the general population in northern China. Environmental Science $\mathcal{E}$ Technology, 43(18): 6963-6968.

Zuo Q, Lin H, Zhang X L, Li Q L, Liu S Z, Tao S, 2006. A two-compartment exposure device for foliar uptake study. Environmental Pollution, 143(1): 126-128. 